\title{
Comment on Article "Net Energy Analysis of Gas Production from the Marcellus Shale" by Devin Moeller and David Murphy
}

\author{
Michael Aucott ${ }^{1}$
}

Received: 21 February 2017 / Accepted: 18 April 2017 / Published online: 26 April 2017

(C) Springer International Publishing Switzerland 2017

The article "Net Energy Analysis of Gas Production from the Marcellus Shale" by Devin Moeller and David Murphy was useful; it adds to the literature on gas production from the Marcellus that includes the referenced articles by my co-author and me (Aucott and Melillo 2013; Yaritani and Matsushima 2014). However, there are several aspects that call for comment. First, Moeller and Murphy include additional energy expended on well workovers, but they do not indicate whether any additional production could be expected from these workovers. If there was additional production, total production from these wells would have been larger, and the EROI larger as well. Second, their statement that our analysis ended at the well gate and did not include the lease/plant energy is not correct. We included the energy used to process and compress gas to distribute it to end-use customers by subtracting $8.2 \%$ from the total production. Because this is "self-use" gas, i.e., gas that is used directly in the initial stages of processing and distribution, and would not have been accessible to humanity unless the well was drilled and fracked, we subtracted this quantity from the production quantity and thus placed it in the numerator of the ratio calculation, not the denominator. Third, the chief difference between the Yaritani and Matsushima analysis and ours is that these authors included the processing and distribution energy in the denominator, rather than subtracting it from the numerator (production) quantity as we did. Had these authors performed the same calculation we did, subtracting the processing and

This is a commentary to article doi:10.1007/s41247-016-0006-8.

Michael Aucott

aucott@ verizon.net

1 The College of New Jersey, Ewing, NJ, USA distribution energy from the total production, their EROI would have been larger than ours.

Michael Aucott

Compliance with Ethical Standards

Conflict of interest No conflict of interest exists.

\section{References}

Aucott ML, Melillo J (2013) A preliminary energy return on investment analysis of natural gas from the Marcellus shale. J Ind Ecol 17(5):668-679

Yaritani H, Matsushima J (2014) Analysis of the energy balance of shale gas development. Energies 7:2207-2227 